This is a pre-print version of the article. Please note that there may be deviations between this and the final article.

\title{
What counts as Aesthetics in Science? A Bibliometric Analysis and Visualization of the Scientific Literature from 1970 to 2018.
}

$$
\text { Manuel Anglada-Tort*1 and Martin Skov². }
$$

${ }^{1}$ Department of Audio Communication, Technische Universität Berlin, Germany.

${ }^{2}$ Danish Research Centre for Magnetic Resonance, Copenhagen University Hospital Hvidovre, Denmark and Decision Neuroscience Research Cluster, Copenhagen Business School, Denmark.

*Corresponding author information: Manuel Anglada-Tort, Department of Audio Communication, Technische Universität Berlin, Einsteinufer 17, 10587 Berlin, Germany. E-mail: m.angladatort@campus.tu-berlin.de

Data availability statement: The data that supports the findings of this study are openly available at https://doi.org/10.5281/zenodo.3555589

Acknowledgements: This work was supported by a PhD studentship from the "Studienstiftung des Deutschen Volkes" (Bonn, Germany) awarded to Manuel AngladaTort. 


\begin{abstract}
Many scientific disciplines give rise to research published under the moniker of aesthetics. For instance, both psychology and neuroscience have highly active subfields focused on aesthetics research, known as empirical aesthetics and neuroaesthetics. However, it remains unclear what aesthetics is about, and, consequently, if aesthetics research pursued by different scientific disciplines addresses common problems. It is therefore difficult to assess how well aesthetics is doing as a scientific enterprise, identify and compare its main subfields, and quantify its productivity and developments. To give an unbiased account of what counts as aesthetics across scientific disciplines, we conducted a bibliometric analysis of every publication found in Web of Science tagged as aesthetics. Spanning 1970 to 2018, the retrieved literature comprised a total of 27,159 papers, 45,832 authors, and 123 countries. Visualization and bibliometric techniques were used to investigate the main research trends and subfields, growth of publications, citation analysis, and country productivity and collaborations. With a total growth rate of $10.2 \%$, there was a clear increase in aesthetics research over time. The retrieved documents received a total of 217,93 citations, with a mean of 8.02 citations per document $(S D=25.7)$. Both a cluster analysis of the data, and a comparative analysis a posteriori, revealed that the aesthetics literature clusters into distinct research areas that differ significantly in their object of interest, research productivity and impact. This finding suggests that aesthetics is better thought of as a confederate of research traditions than a whole unified by common problems and research strategies.
\end{abstract}

Keywords: aesthetics, bibliometrics, Web of Science, psychology, neuroscience 


\section{WHAT COUNTS AS AESTHETICS IN SCIENCE?}

\section{Introduction}

The word aesthetics first entered the academic discourse in a 1735 thesis on poetry by the German philosopher Alexander Gottlieb Baumgarten (1735/1954). Only a few decades later it had been naturalized into most other European languages, and was, by the 1790s, used widely as the name of one of philosophy's core areas of inquiry (Reiss, 1994). Not long after, in the mid-nineteenth century, aesthetics was taken up as part of the nascent field of experimental psychology, giving rise to what today is known as empirical aesthetics (Allesch, 1987; Fechner, 1876; Nadal, Gomila \& Gálvez-Pol, 2014). Today, many scientific disciplines produce research under the moniker of aesthetics, including neuroscience, where the last twenty years have seen the rise of a subfield in cognitive neuroscience called neuroaesthetics (Chatterjee \& Vartanian, 2014; Huston et al., 2015; Nadal \& Pearce, 2011; Pearce et al., 2016; Skov \& Vartanian, 2009).

Yet, despite its evident allure, in many ways it remains unclear what aesthetics is about, or if work produced by different disciplines under that name has much in common. If we take empirical aesthetics and neuroaesthetics as examples, it is, for instance, far from obvious what, to these disciplines, constitutes an aesthetic problem. Introductions to psychological aesthetics and neuroaesthetics are notoriously idiosyncratic (e.g., Brattico \& Pearce, 2013; Brielmann \& Pelli, 2018; Chatterjee, 2011; Chatterjee \& Vartanian, 2016; Di Dio \& Gallese, 2009; Hodges, 2018; Nadal \& Pearce, 2011; Pearce et al., 2016; [BLINDED]). Thus, some underscore the primacy of art to a definition of what aesthetics is: "Neuroaesthetics is a term coined by Zeki and refers to the study of the neural basis of beauty perception in art" (Di Dio \& Gallese, 2009, p. 682). Others link aesthetics specifically to the phenomenon of appreciation, irrespective 


\section{WHAT COUNTS AS AESTHETICS IN SCIENCE?}

of the kind of stimulus being appreciated: "aesthetic processing - the evaluation or production of beauty, ugliness, prettiness, harmony, elegance, shapeliness or charm" (Jacobsen, 2006, p. 155). As noted by Anjan Chatterjee, in psychology and neuroscience the term aesthetic can be used "broadly to encompass the perception, production, and response to art, as well as interactions with objects and scenes that evoke an intense feeling, often of pleasure" (Chatterjee, 2011, p. 53).

It is also unclear who, in fact, are engaged in aesthetics research, or if work produced by psychologists or neuroscientists is recognized as bona fide contributions to "real" aesthetics by scholars in, say, philosophy or art history (Pearce et al., 2016; [BLINDED]). Many researchers outside psychology and neuroscience have voiced strong skepticism about the ability of psychological and neuroscientific methods to produce knowledge that have any bearing on topics that are of importance to aesthetics (Croft, 2011; Dickie, 1962; Hyman, 2006; Meskin, 2018; Noë, 2015). Meanwhile, inside the broader confines of psychology and neuroscience it is often unclear how work into aesthetics can be demarcated from other forms of research. For example, mainstream psychologists and neuroscientists dedicate much effort to the understanding of how pleasure is generated, and what role it plays in forming motivated behavior (Becker et al., 2019; Berridge \& Kringelbach, 2015; Rangel, Camerer \& Montague, 2008; van Steenbergen, Eikemo \& Leknes, 2019). Are studies in neuroaesthetics investigating "aesthetic" liking part of this general effort, or does "aesthetic" pleasure constitute a separate psychological and neuroscientific topic (Skov, 2019; [BLINDED])? There is no universally accepted answer to this question.

This lack of a concise and universally agreed definition of what aesthetics is has many ramifications for the status of aesthetics as a scientific enterprise (Naukkarinen \& Bragge, 2016). First of all, it renders it uncertain which kind of study belongs to the 


\section{WHAT COUNTS AS AESTHETICS IN SCIENCE?}

field of aesthetics, and which does not. Secondly, it makes it ambiguous how well aesthetics is doing as a scientific enterprise, what the latest trends are, and what subfields excel and which do not. Finally, it obscures what precisely distinguish disciplines such as art history, empirical aesthetics, and dental surgery. If aesthetics wants to advance as a scientific study, it must be put on a firmer conceptual footing. The aim of this paper is to help further this ambition by analyzing what, as a matter of scientific practice, counts as a topic in aesthetics. Instead of presenting a normative argument of what must count as topic in aesthetics, we examine what is considered aesthetics as matter of scientific record. Specifically, we analyze all available research that has been published under the name of "aesthetics" in the modern scientific literature. Such an approach, we believe, has the clear advantage that it makes no theoretical assumptions about what is and is not aesthetics, and thus is not biased in its analysis.

To accomplish this goal, we conducted a large-scale computational bibliometric analysis of the scientific literature published between 1970 and 2018, asking what kind of research the word "aesthetics" has been associated with, across disciplines. Bibliometrics is a set of methods to quantitatively analyze scientific publications, yielding objective and measurable data to increase our understanding of the composition and trajectory of a specific group of publications (De Bellis, 2009; Garfield, 1972). Bibliometrics can analyze quantitative and qualitative aspects of an academic field or research area even when this involves processing thousands of papers, citation and authorship analysis, country productivity, collaborations, impact of publications, and research trends (e.g., Anglada-Tort \& Sanfilippo, 2019; Chen, Arsenault, Gingras, \& Larivière, 2015; Mryglod, Holovatch, Kenna, \& Berche, 2016; Naukkarinen \& Bragge, 2016; Sweileh, 2017; Sweileh, Al-Jabi, Sawalha, \& Zyoud, 2016). 


\section{WHAT COUNTS AS AESTHETICS IN SCIENCE?}

To date, only one bibliometric analysis has analyzed modern scientific output with a specific focus on aesthetics (Naukkarinen \& Bragge, 2016). However, this study explicitly limited its focus to publications from the arts and humanities, and did not survey trends across all scientific disciplines. Moreover, Naukkarinen \& Bragge (2016) used few bibliometric indicators to analyze their dataset. For example, their study did not provide information about the growth of publications, citation analysis, or country productivity and collaborations. In contrast, we aim to characterize aesthetics as an academic enterprise in toto, showing how aesthetics research has developed from 1970 to today: what types of research has, irrespective of tradition, been undertaken, how much of it has been published and cited in any given year, and which have been the most influential concepts, subfields, and countries. Our analysis also attempts to show how different topics cluster within different academic disciplines, revealing commonalities and differences in what different disciplines consider an aesthetic problem.

The present study therefore analyzed all peer-reviewed articles available in Web of Science (WoS) using the keyword aesthetics. This dataset comprised a total of 27,169 papers, 45,832 authors, and 7,893 journals. We used the R package Bibliometrix (Aria \& Cuccurullo, 2017) to systematically analyze the retrieved literature. To visualize the data, we used VOSviewer (Van Eck \& Waltman, 2010), a software tool that applies advanced clustering and natural language processing techniques for generating and visualizing maps based on network data. VOSviewer has been used in a large body of published literature (http://www.vosviewer.com/publications), generating over 500 publications since 2006. In analyzing the data, we first provide a general overview of the literature tagged as aesthetics, focusing on four key aspects: (1) the main conceptual language used and how different topics relate to each other and cluster 


\section{WHAT COUNTS AS AESTHETICS IN SCIENCE?}

together, (2) growth of publications, (3) citation analysis, and (4) country analysis. In a second analysis, we probe differences between the five main research categories provided by WoS: Arts \& Humanities, Life Sciences, Technology, Physical Sciences, and Social Sciences. Finally, we probe publications indexed as representative of psychology and neuroscience to specifically identify how empirical aesthetics is distinguished from other aesthetics traditions.

\section{Method}

\section{Data Collection and Search Strategy}

Data collection consisted of two stages. In both stages, we retrieved the literature from WoS, one of the worlds' largest and most influential scientific databases. In 2017, it contained over 90 million records, 12,000 high impact journals, and 160,000 conference proceedings (Thomson, 2017). The content for WoS is determined by a strict assessment and selection process based on impact, influence, quality, peer review, and geographic representation (Thomson, 2010). For the present study, WoS was particularly suitable because it allowed us to retrieve more than 2,000 publications in the required formats (i.e., "bib" and "text" files), including all relevant bibliometric data.

In the first stage, we searched all available literature containing the keywords aesthetics or esthetics in either the title, the abstract, or author keywords. We limited the search to only peer-reviewed publications (research articles, reviews, or conference papers), excluding book chapters, editorial notes, and letters. We also excluded literature published in 2019 (the year in which the study was conducted). The resulting publications were exported to "bib" and "text" files. When available, the data for each publication included the document's title, abstract, keywords, author(s), year of publication, journal (with volume, issue, and pages), citation count, document type, 


\section{WHAT COUNTS AS AESTHETICS IN SCIENCE?}

DOI, author affiliations, serial identifiers, publisher, editor, language of original document, and correspondence address. The data was retrieved on July 18, 2019 ([Insert link here]). This dataset was used for the general analysis provided in section 1 .

In the second stage, we compared publications as they organized into different research areas. To minimize subjective bias in the classification of publications into different research areas, we used the five research categories provided by $\mathrm{WoS}^{1}$ : Arts \& Humanities, Life Sciences \& Biomedicine, Physical Sciences, Social Sciences, and Technology. We conducted five separate database searches to download the literature belonging to each of these five areas. In addition, to examine the use of "aesthetics" specifically in psychology and neuroscience publications, we conducted a search to download all literature classified in the categories psychology and neuroscience from WoS. The analysis strategy in the six searchers was the same as employed in the first stage, i.e., searching for all available literature containing the keywords aesthetics or esthetics in either the title, the abstract, or the author keywords. Again, publications from 2019 were excluded, and only peer-reviewed publications were included, namely, research articles, reviews, or conference papers. The data was retrieved on September 12, 2019 ([Insert link here]). This dataset was used for the comparative analysis provided in section 2 .

\section{Data Analysis and Visualization}

Descriptive statistics and standard bibliometric indicators (i.e., citation analysis, annual growth of publications, authorship productivity, dominance, collaboration index, and country productivity) were used to produce an overview of the retrieved data. The application and presentation of part of these indicators was based on the analysis

\footnotetext{
${ }^{1}$ https://images.webofknowledge.com/WOKRS511B5/help/WOS/hp_research_areas_easca.html
} 


\section{WHAT COUNTS AS AESTHETICS IN SCIENCE?}

reported in Anglada-Tort and Sanfilippo (2019). The R package bibliometrix (Aria \& Cuccurullo, 2017) was used to perform the bibliometric analysis, including descriptive statistics, citation analysis, authorship and country analysis, and collaborations. Visualization and Bibliometric maps were created using VOSviewer (Van Eck \& Waltman, 2010), which uses a unified framework for mapping and clustering (Waltman, Van Eck, \& Noyos, 2010). The software is mainly intended for analysis of bibliometric networks and to create network visualizations maps. In the network maps, items are represented by their label and by a circle. The size of the circles is determined by the weight of the item. The place of the items in the map and their colors are used to cluster the items. The color of an item is determined by the cluster to which the item belongs. Lines between items represent links and the stronger the link is, the wider the line. The distance between items in the map indicates the degree of relatedness between them. Furthermore, we used the R package rworldmap (South, 2011) to generate visualizations of the world's geographical distribution of countries' productivity.

\section{Results}

\section{Aesthetics as a whole}

\section{Retrieved Literature}

The retrieved literature covered a period of 49 years (1970-2018) and comprised a total of 27,169 documents published in 7,893 journals. A total of 45,832 authors were covered in the retrieved literature, with a mean of 1.69 authors per document and a mean of .59 articles per author. The mean number of co-authors per article was 2.27 and the total collaboration index (number of authors in multi-authored publications/ number of multi-authored papers) was 1.68 . The vast majority of documents were research articles $(81.62 \%)$, whereas conference proceedings $(15.36 \%)$ and review articles 
WHAT COUNTS AS AESTHETICS IN SCIENCE?

(3.01\%) only represented a minimal portion. Table 1 shows the top 20 contributions made by author keyword, journal, and country.

Table 1. Top 20 contributions by keyword, journal, and country.

\begin{tabular}{|c|c|c|c|c|c|}
\hline Keyword & TP & Journal & $\mathrm{TP}$ & Country* & $\mathrm{TP}$ \\
\hline Aesthetics & 3420 & Journal of prosthetic dentistry & 274 & US & 75452 \\
\hline Esthetics & 573 & $\begin{array}{l}\text { American Journal of Orthodontics } \\
\text { and Dentofacial Orthopedics }\end{array}$ & 245 & UK & 24081 \\
\hline Art & 438 & Plastic and Reconstructive Surgery & 180 & Germany & 11189 \\
\hline Dental Implants & 273 & Journal of Craniofacial Surgery & 172 & Canada & 10914 \\
\hline Ethics & 262 & $\begin{array}{l}\text { British Journal of Aesthetics } \\
\text { Journals of Aesthetics and Art }\end{array}$ & 168 & Australia & 9997 \\
\hline Beauty & 226 & Criticism & 152 & Italy & 7593 \\
\hline Design & 207 & Quintessence International & 129 & Netherlands & 6247 \\
\hline Perception & 164 & Journal of Aesthetic Education & 127 & Switzerland & 5925 \\
\hline Architecture & 152 & $\begin{array}{l}\text { Journal of Periodontology } \\
\text { International Journal of Oral and }\end{array}$ & 127 & China & 5081 \\
\hline Music & 138 & Maxillofacial Surgery & 125 & Brazil & 4531 \\
\hline Creativity & 135 & Angle Orthodontist & 117 & Belgium & 4339 \\
\hline Modernism & 134 & $\begin{array}{l}\text { Clinical Oral Implants Research } \\
\text { International Journal of Periodontics }\end{array}$ & 116 & Sweden & 3876 \\
\hline Performance & 134 & $\begin{array}{l}\text { \& Restorative Dentistry } \\
\text { Journal of Esthetic and Restorative }\end{array}$ & 113 & Israel & 3209 \\
\hline Politics & 133 & Dentistry & 107 & Spain & 3194 \\
\hline Quality of Life & 124 & Landscape and Urban Planning & 103 & France & 3179 \\
\hline Education & 120 & Aesthetic Plastic Surgery & 95 & Turkey & 2583 \\
\hline Culture & 118 & $\begin{array}{l}\text { Journal of Prosthodontics-Implant } \\
\text { and Reconstructive Dentistry } \\
\text { Journal of Oral and Maxillofacial }\end{array}$ & 95 & Taiwan & 2365 \\
\hline Emotion & 117 & Surgery & 92 & Korea & 2319 \\
\hline Aesthetic & 113 & $\begin{array}{l}\text { Leonardo } \\
\text { Journal of Cranio-Maxillofacial }\end{array}$ & 89 & Japan & 2285 \\
\hline Gender & 110 & Surgery & 78 & Denmark & 1804 \\
\hline
\end{tabular}




\section{WHAT COUNTS AS AESTHETICS IN SCIENCE?}

Conceptual map of aesthetics as a whole

Figure 1 shows a network visualization map of author keywords co-occurrences (i.e., keywords listed by the authors on each publication). Only keywords that occurred a minimum of 30 times were included ${ }^{2}$, resulting in a total of 205 keywords organized in five clusters. Table 2 shows the top 10 most frequent keywords in each of the five clusters.

Figure 1. Network visualization map of keyword occurrences.

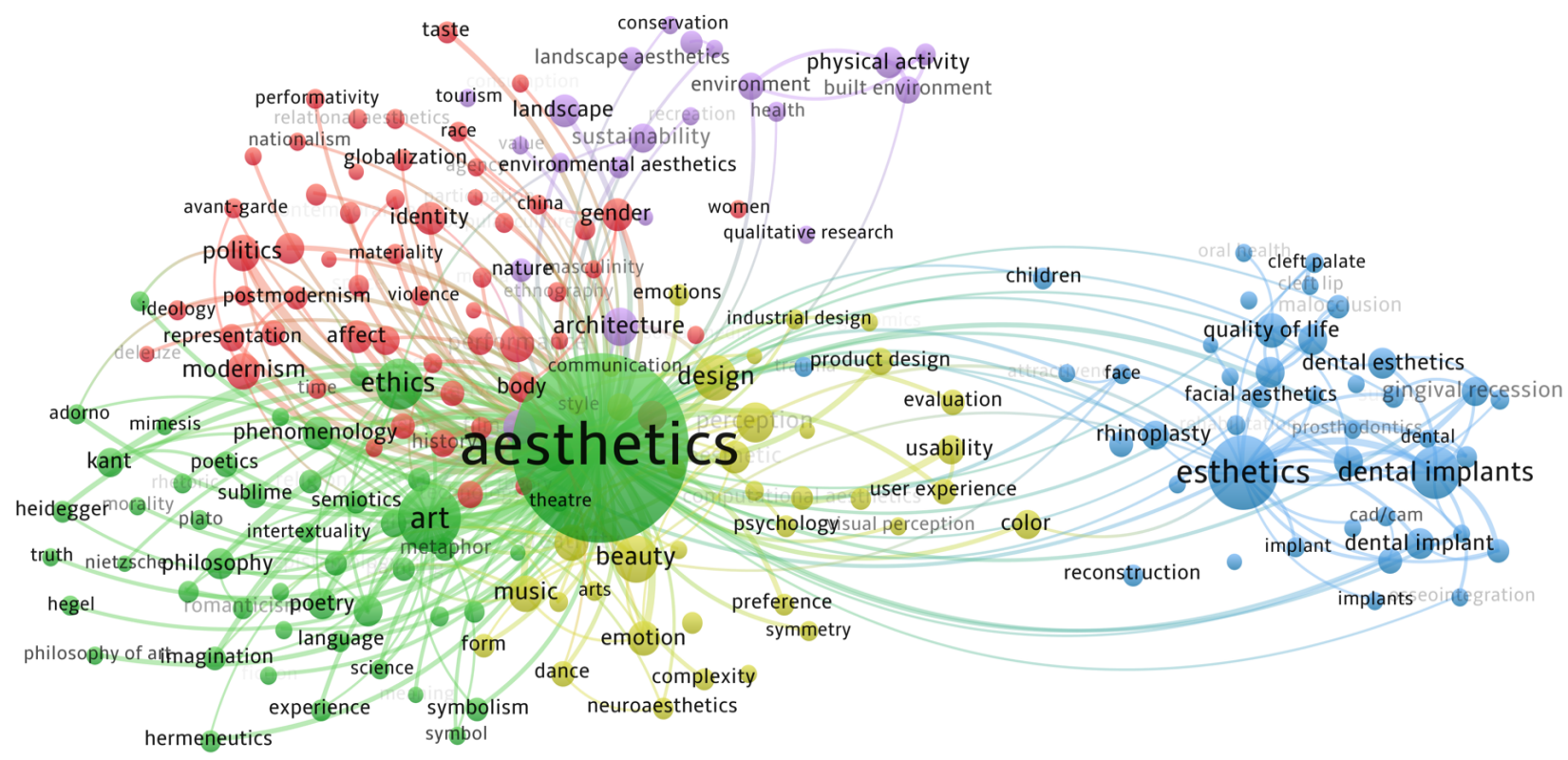

Note. The size of the circle indicates the total number of occurrences. Lines represent

the connection between keyword based on their relatedness and the stronger the link is, the wider the line. The color of the circle indicates the cluster that the keywords belong to.

\footnotetext{
${ }^{2}$ Note that the maps generated by VOSviewer are sensitive to several parameters in the software, such as the number of co-occurrences. However, the main structure of the map remains similar when these parameters are modified.
} 
WHAT COUNTS AS AESTHETICS IN SCIENCE?

Table 2. Top 10 most frequent keywords in each of the five clusters

\begin{tabular}{|c|c|c|c|c|c|c|c|c|c|}
\hline $\begin{array}{l}\text { Red Cluster } \\
\text { (Humanities) }\end{array}$ & $\mathrm{N}$ & $\begin{array}{l}\text { Green } \\
\text { Cluster } \\
\text { (Philosoph } \\
\text { y) }\end{array}$ & $\mathrm{N}$ & $\begin{array}{l}\text { Yellow } \\
\text { Cluster } \\
\text { (Empirical } \\
\text { Aesthetics) }\end{array}$ & $\mathrm{N}$ & $\begin{array}{l}\text { Blue } \\
\text { Cluster } \\
\text { (Reconstruct } \\
\text { ive Surgery) }\end{array}$ & $\mathrm{N}$ & $\begin{array}{l}\text { Purple } \\
\text { Cluster } \\
\text { (Environmental } \\
\text { Aesthetics) }\end{array}$ & $\mathrm{N}$ \\
\hline modernism & 135 & art & 437 & beauty & 226 & $\begin{array}{l}\text { dental } \\
\text { implants } \\
\text { quality of }\end{array}$ & 270 & architecture & 151 \\
\hline performance & 134 & ethics & 262 & design & 206 & $\begin{array}{l}\text { life } \\
\text { dental }\end{array}$ & 123 & culture & 118 \\
\hline politics & 133 & $\begin{array}{l}\text { education } \\
\text { phenomen }\end{array}$ & 115 & perception & 164 & $\begin{array}{l}\text { esthetics } \\
\text { orthodontic }\end{array}$ & 97 & $\begin{array}{l}\text { landscape } \\
\text { physical }\end{array}$ & 102 \\
\hline gender & 110 & ology & 105 & music & 138 & $\begin{array}{l}\mathrm{s} \\
\text { patient }\end{array}$ & 97 & activity & 99 \\
\hline identity & 108 & poetry & 100 & creativity & 135 & $\begin{array}{l}\text { satisfaction } \\
\text { dental }\end{array}$ & 97 & sustainability & 85 \\
\hline affect & 103 & literature & 91 & emotion & 116 & $\begin{array}{l}\text { implant } \\
\text { orthognathi }\end{array}$ & 93 & $\begin{array}{l}\text { environment } \\
\text { built }\end{array}$ & 78 \\
\hline photography & 101 & kant & 90 & aesthetic & 113 & $\begin{array}{l}\text { c surgery } \\
\text { gingival }\end{array}$ & 91 & environment & 74 \\
\hline body & 99 & realism & 75 & $\begin{array}{l}\text { usability } \\
\text { aesthetic }\end{array}$ & 87 & recession & 87 & $\begin{array}{l}\text { nature } \\
\text { landscape }\end{array}$ & 58 \\
\hline modernity & 97 & poetics & 65 & $\begin{array}{l}\text { experience } \\
\text { product }\end{array}$ & 79 & rhinoplasty & 81 & $\begin{array}{l}\text { aesthetics } \\
\text { ecosystem }\end{array}$ & 58 \\
\hline memory & 91 & sublime & 64 & design & 76 & satisfaction & 68 & services & 57 \\
\hline
\end{tabular}

\section{Growth in Number of Publications}

Figure 2 shows the total number of publications over time, which increased significantly over time, as indicated by cubic linear regression, $F(3,45)=456, p<.001$, $R^{2}=.968$. The mean number of publications per year from 1970 to 2018 was 554.43 $(S D=783.51)$. The total annual percentage growth rate was $10.2 \%$. The highest 
WHAT COUNTS AS AESTHETICS IN SCIENCE?

productivity was observed in 2017 with a total of 2,988 publications $(11 \%)$ and the lowest productivity was observed in 1974 with a total of 12 publications $(.04 \%)$.

Figure 2. Total number of publications per year.

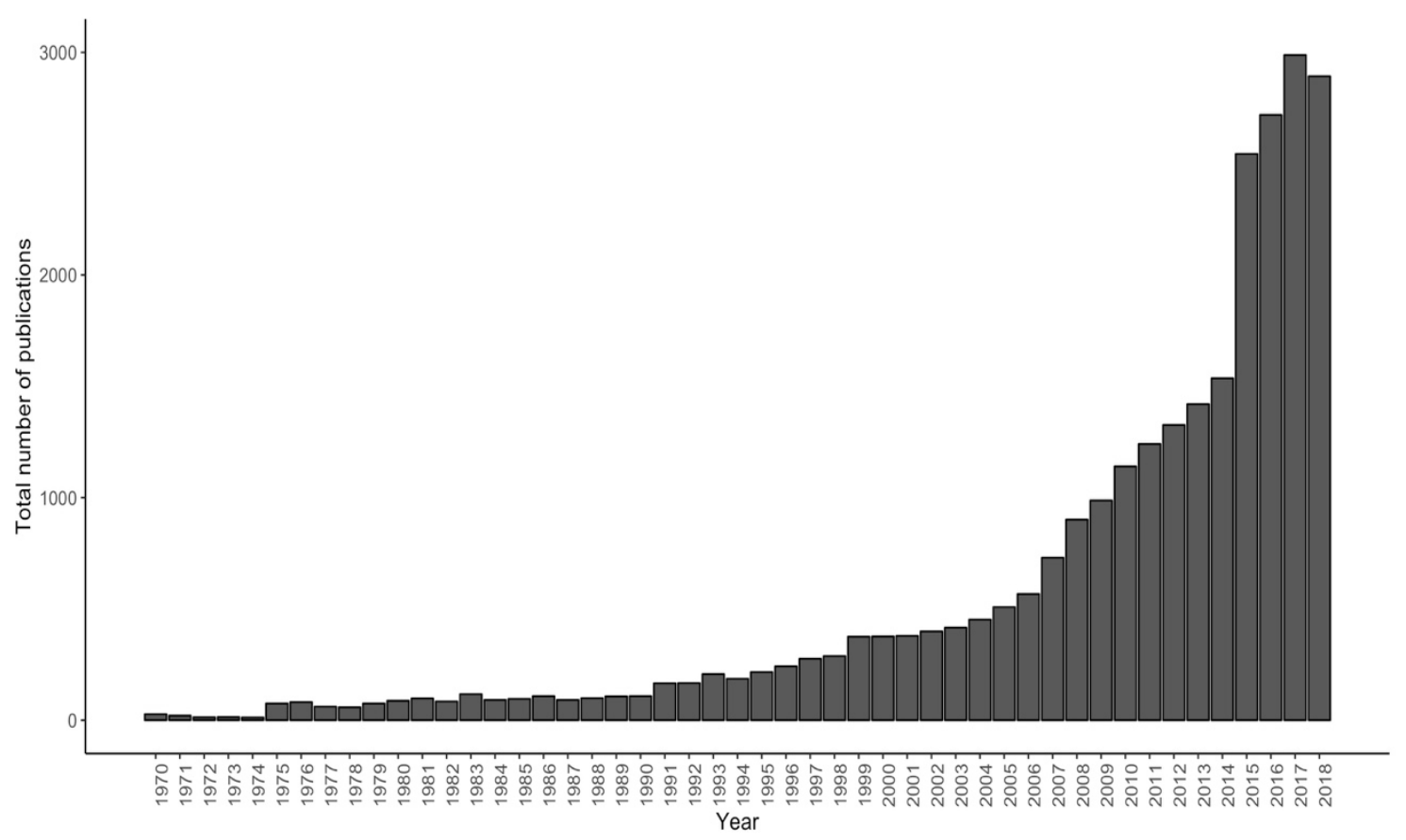

Table 3 shows the annual number of publications, annual growth rate (AGR), and relative growth rate (RGR). The AGR indicates the percentage of change in the number of publications over one year and is calculated using the following equation: $A G R=[(T P$ ending value - TP beginning value $) / T P$ beginning value $] * 100$, where TP is total number of publications. The RGR indicates the growth rate relative to the total number of publications per year and is calculated based on the following equation: $R G R=\left[\log _{e} W_{2}-\log _{e} W_{1}\right] /(T 2-T 1)$, where $\log _{\mathrm{e}} \mathrm{W}_{2}$ is the $\log$ of the final number of publications after a specific period of interval; $\log _{\mathrm{e}} \mathrm{W}_{1}$ is the $\log$ of the initial number of publications; and T1-T2 is the unit difference between the initial time and the final time. 
Table 3. Annual number of publications, AGR, and RGR.

\begin{tabular}{|c|c|c|c|c|c|}
\hline Year & ТP (\%) & AGR & $\mathrm{CT}$ & $\log _{e} W$ & RGR \\
\hline 1970 & $27(0.1)$ & - & 17 & 2.83 & - \\
\hline 1971 & $20(0.07)$ & -0.26 & 37 & 3.61 & 0.78 \\
\hline 1972 & $13(0.05)$ & -0.35 & 50 & 3.91 & 0.30 \\
\hline 1973 & $14(0.05)$ & 0.08 & 64 & 4.16 & 0.25 \\
\hline 1974 & $12(0.04)$ & -0.14 & 76 & 4.33 & 0.17 \\
\hline 1975 & $75(0.28)$ & 5.25 & 151 & 5.02 & 0.69 \\
\hline 1976 & $81(0.3)$ & 0.08 & 232 & 5.45 & 0.43 \\
\hline 1977 & $61(0.22)$ & -0.25 & 293 & 5.68 & 0.23 \\
\hline 1978 & $58(0.21)$ & -0.05 & 351 & 5.86 & 0.18 \\
\hline 1979 & $75(0.28)$ & 0.29 & 426 & 6.05 & 0.19 \\
\hline 1980 & $87(0.32)$ & 0.16 & 513 & 6.24 & 0.19 \\
\hline 1981 & $98(0.36)$ & 0.13 & 611 & 6.42 & 0.17 \\
\hline 1982 & $84(0.31)$ & -0.14 & 695 & 6.54 & 0.13 \\
\hline 1983 & $117(0.43)$ & 0.39 & 812 & 6.70 & 0.16 \\
\hline 1984 & $91(0.33)$ & -0.22 & 903 & 6.81 & 0.11 \\
\hline 1985 & $96(0.35)$ & 0.05 & 999 & 6.91 & 0.10 \\
\hline 1986 & $108(0.4)$ & 0.13 & 1107 & 7.01 & 0.10 \\
\hline 1987 & $91(0.33)$ & -0.16 & 1198 & 7.09 & 0.08 \\
\hline 1988 & $99(0.36)$ & 0.09 & 1297 & 7.17 & 0.08 \\
\hline 1989 & $107(0.39)$ & 0.08 & 1404 & 7.25 & 0.08 \\
\hline 1990 & $108(0.4)$ & 0.01 & 1512 & 7.32 & 0.07 \\
\hline 1991 & $166(0.61)$ & 0.54 & 1678 & 7.43 & 0.10 \\
\hline 1992 & $167(0.61)$ & 0.01 & 1845 & 7.52 & 0.09 \\
\hline 1993 & $207(0.76)$ & 0.24 & 2052 & 7.63 & 0.11 \\
\hline 1994 & $186(0.68)$ & -0.10 & 2238 & 7.71 & 0.09 \\
\hline 1995 & $216(0.8)$ & 0.16 & 2454 & 7.81 & 0.09 \\
\hline 1996 & $242(0.89)$ & 0.12 & 2696 & 7.90 & 0.09 \\
\hline 1997 & $276(1.02)$ & 0.14 & 2972 & 8.00 & 0.10 \\
\hline 1998 & $288(1.06)$ & 0.04 & 3260 & 8.09 & 0.09 \\
\hline 1999 & $375(1.38)$ & 0.30 & 3635 & 8.20 & 0.11 \\
\hline 2000 & $376(1.38)$ & 0.00 & 4011 & 8.30 & 0.10 \\
\hline 2001 & 379 (1.39) & 0.01 & 4390 & 8.39 & 0.09 \\
\hline 2002 & $399(1.47)$ & 0.05 & 4789 & 8.47 & 0.09 \\
\hline 2003 & $416(1.53)$ & 0.04 & 5205 & 8.56 & 0.08 \\
\hline 2004 & $452(1.66)$ & 0.09 & 5657 & 8.64 & 0.08 \\
\hline 2005 & $508(1.87)$ & 0.12 & 6165 & 8.73 & 0.09 \\
\hline 2006 & $567(2.09)$ & 0.12 & 6732 & 8.81 & 0.09 \\
\hline 2007 & $730(2.69)$ & 0.29 & 7462 & 8.92 & 0.10 \\
\hline 2008 & $901(3.32)$ & 0.23 & 8363 & 9.03 & 0.11 \\
\hline 2009 & $987(3.63)$ & 0.10 & 9350 & 9.14 & 0.11 \\
\hline 2010 & $1140(4.2)$ & 0.16 & 10490 & 9.26 & 0.12 \\
\hline
\end{tabular}


WHAT COUNTS AS AESTHETICS IN SCIENCE?

\begin{tabular}{lccccc}
2011 & $1241(4.57)$ & 0.09 & 11731 & 9.37 & 0.11 \\
2012 & $1326(4.88)$ & 0.07 & 13057 & 9.48 & 0.11 \\
2013 & $1420(5.23)$ & 0.07 & 14477 & 9.58 & 0.10 \\
2014 & $1536(5.65)$ & 0.08 & 16013 & 9.68 & 0.10 \\
2015 & $2544(9.36)$ & 0.66 & 18557 & 9.83 & 0.15 \\
2016 & $2719(10.01)$ & 0.07 & 21276 & 9.97 & 0.14 \\
2017 & $2988(11)$ & 0.10 & 24264 & 10.10 & 0.13 \\
2018 & $2893(10.65)$ & -0.03 & 27157 & 10.21 & 0.11 \\
\hline
\end{tabular}

Note. TP: Total publications; AGR: Annual growth rate; CT: Cumulative total; RGR:

Relative growth rate.

\section{Citation Analysis}

Figure 3 shows the average total number of citations over time. The relationship between the average citations and year followed an inverted- $U$ shape, as indicated by a statistically significant cubic regression, $F(3,45)=39.3, p<.001, R^{2}=.724$. Retrieved documents received a total of 217,931 citations, a mean of $8.02(S D=25.7)$ citations per document, and median $(\mathrm{Q} 1-\mathrm{Q} 3)$ of $1(0-6)$. While the highest number of citations per document was in 2010, with 10,038 citations, the lowest was in 1974 with 9 citation (see Appendix A for a summary of the citation analysis per year). 
Figure 3. Average citations per year.

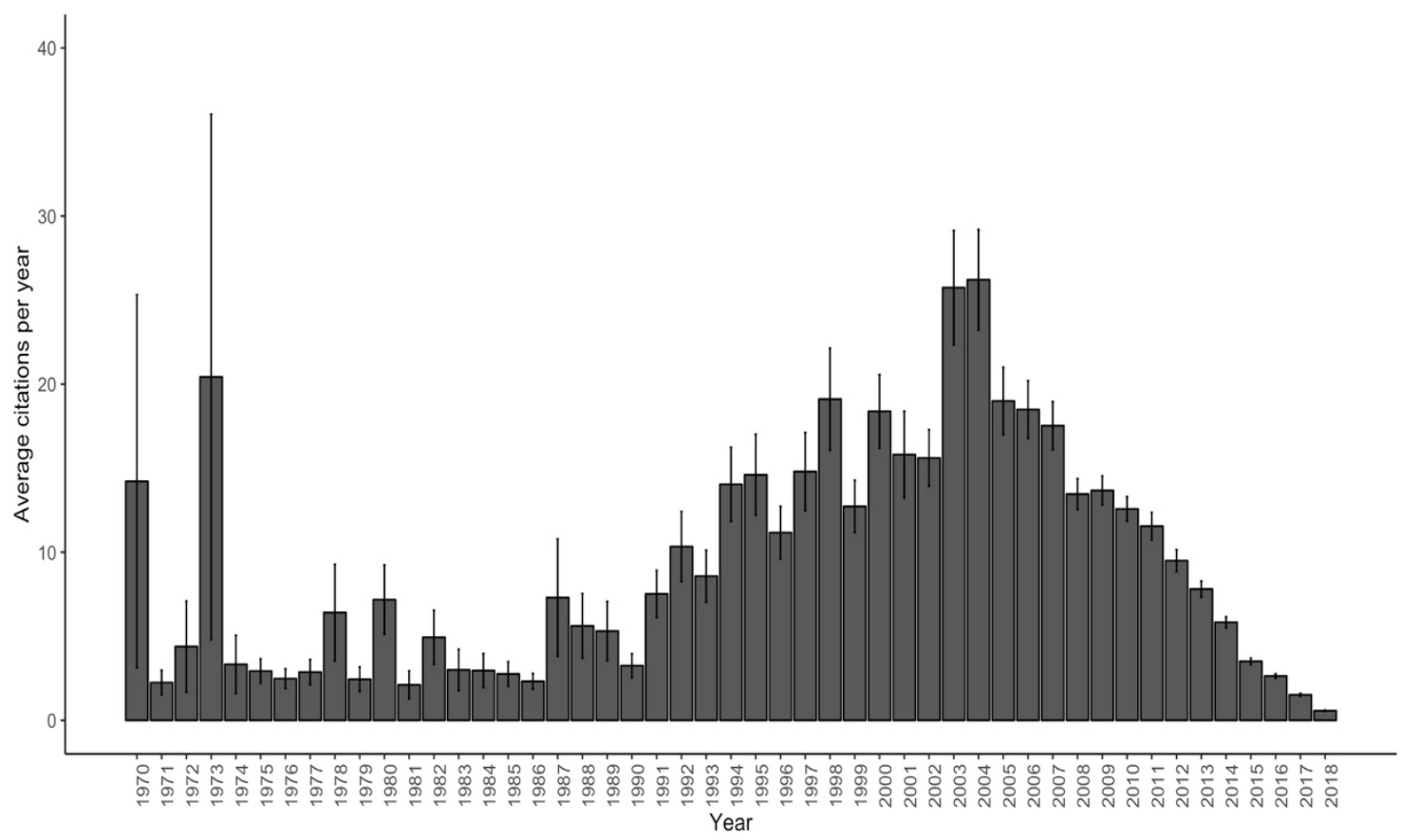

Note. Error bar represent standard error.

Country Analysis: Productivity, Collaborations, and Geographical Distribution

A total of 123 countries contributed to the retrieved literature (see Appendix B for a Table with the top 20 most productive countries, including number of publications and citations). Figure 4 depicts a network visualization map of international collaborations. Countries with a minimum of 100 international co-authorship publications and a minimum of 100 total citations are visualized. As a result, 46 countries are visualized, clustering in 7 groups. The US and UK were the largest contributors of publications, with 6,622 (24.37\%) and 2,359 (8.68\%) publications, respectively, as well as the highest number of citations (US $=75,452$ and $U K=10,21$ ). Nevertheless, this analysis did not take the population of each country into account. Thus, we ran a second analysis considering the average population for each country. The average population from 1970 to 2018 per country was calculated using the World Bank population data 


\section{WHAT COUNTS AS AESTHETICS IN SCIENCE?}

(https://data.worldbank.org). The total number of publications was divided by the average population for each country (rounded to the nearest million) to find the total number of publications per million people. Once population was accounted for, Slovenia (with 49 publications per million), Denmark (42.2), Australia (41.28), Lithuania (41), and UK (39.98) had the highest total publications. To illustrate this, Figure 5 shows two geographical distributions of publications, a version without correcting for country population (map on the top) and a version correcting for country population (map on the bottom). The maps were created using the R package rworldmap. In the two maps, countries colored in dark blue indicate the highest number of publications, whereas light yellow color represent countries with the lowest number of publications. Countries with no color indicate that there was no retrieved data from these areas.

Figure 4. Network visualization map of international collaborations.

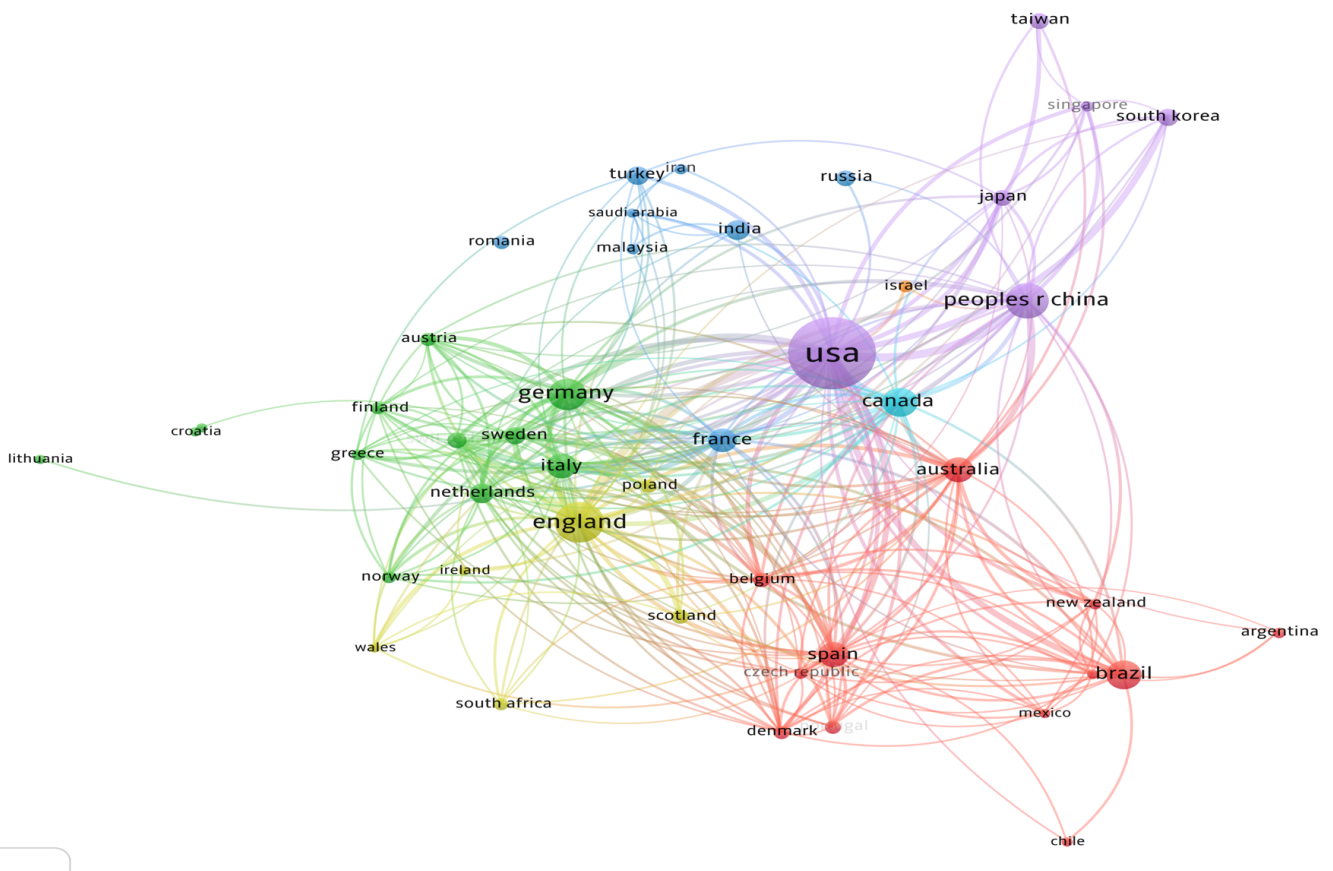




\section{WHAT COUNTS AS AESTHETICS IN SCIENCE?}

Note. The size of the circle indicates the total number of publications per country. The width of the line represents the strength of the collaboration. The color of the circle indicates the cluster to which the country belongs to.

national collaborations.

Figure 5. Geographical distribution of publications without correcting for population (top) and with correction (bottom).
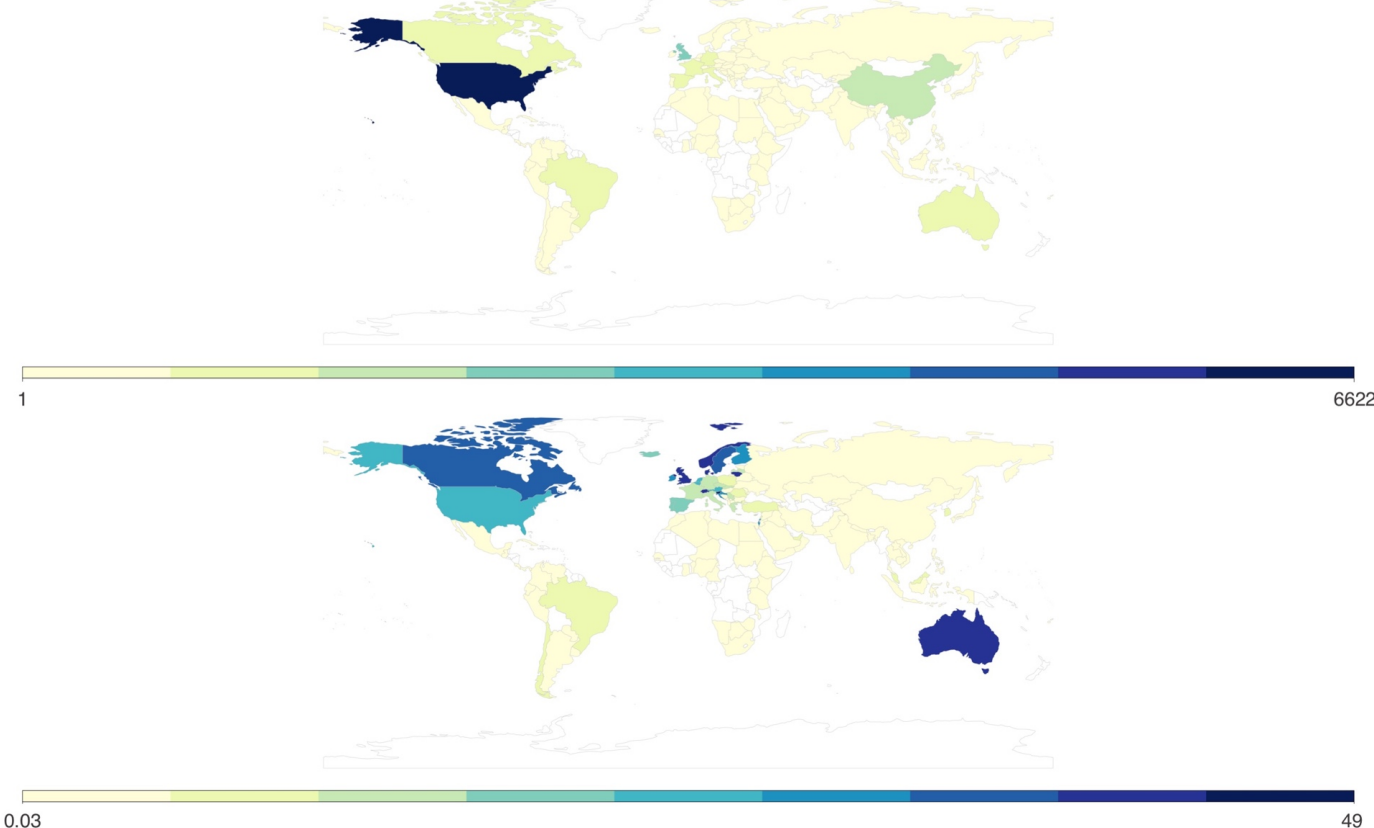

Note. Countries colored dark blue have the highest number of publications and countries colored light yellow the lowest. Countries with no color indicate that there was no retrieved data from these areas.

\section{Differences between academic research areas}

The analysis above attempts to characterize aesthetics as a whole. One of its key findings is that keyword use clusters into five separate domains, suggesting that aesthetics research subdivides into different subfields with different concerns and different scientific questions. We therefore wanted to test how different traditional 


\section{WHAT COUNTS AS AESTHETICS IN SCIENCE?}

research areas might distinguish between types of aesthetics research being conducted. In order to define such research areas as objectively as possible we used the five categories provided by WoS: Arts \& Humanities (A\&H), Life Sciences \& Biomedicine (LS\&B), Physical Sciences (PS), Social Sciences (SS), and Technology (T).

Furthermore, we extracted publications classified as Psychology (P) (including neuroscience) in order to specifically describe the use of aesthetics in psychological and neuroscientific research.

The main bibliometric indicators distinguishing these six research areas are summarized in Table $4^{3}$. Of the six research areas, $\mathrm{A} \& \mathrm{H}$ is responsible for far more aesthetics research than any of the other five areas analyzed here (11,610 publications). However, if we consider the other four WoS research areas (LS\&B, PS, SS, and T) under one - for example as collectively representative of the natural sciences $-14,620$ aesthetics publications have been published outside of A\&H. As regards the outlets used, compared to the other areas, studies in $\mathrm{A} \& \mathrm{H}$ were published in the largest number of journals $(2,504)$. However, if we again lump together the other four main areas as one collective entity, the number of journals is 4,906 . The number of authors involved in aesthetic research also varies across areas. The largest number of authors is found in the LS\&B dataset (15,869 authors), even though it only accounts for half the number of publications produced by A\&H. Furthermore, the collaboration index and annual growth rate for $\mathrm{A} \& \mathrm{H}$ is the lowest compared to the other areas. Finally, the citation analysis also shows significant differences across research areas. Although A\&H is the largest dataset in terms of number of publications, it is also the area with the fewest

\footnotetext{
${ }^{3}$ The general trends in growth of publications over time, citation analysis, and geographical distribution in the six datasets were similar to the results provided in section 1 and, therefore, these analyses are not repeated in this section.
} 
WHAT COUNTS AS AESTHETICS IN SCIENCE?

citations. This is most clear when looking at the average of citations per document $(M=2.24)$.

Figure 6 shows the evolution of the five WoS research areas plus Psychology over time, based on their number of total publications and citations. In general, all research areas increase in number of publications and, to lesser extent, in number of citations. This increase, however, is most prominent in LS\&B compared to the other areas. Finally, the top 10 most frequent keywords in each research area are presented in Table 5. Comparing the top 10 keywords across the six research areas it is very clear that all six produce research quite different in research trends and interests. Not surprisingly, Psychology aligns itself rather well with the yellow cluster in Figure 1. In contrast, research in the A\&H as well as the SS overlap with both the red and green clusters in Figure 1, while research in the LS\&B predominantly conform to the blue cluster. Research in the PS mostly appear to contribute to the purple cluster, whereas research originating in $\mathrm{T}$ is more confuse and does not neatly fit any of the five clusters identified by our keyword analysis in Section 1 .

Table 4. Comparison of research areas using main bibliometric indicators.

\begin{tabular}{|c|c|c|c|c|c|c|}
\hline & $\begin{array}{c}\text { Arts \& } \\
\text { Humanities }\end{array}$ & $\begin{array}{c}\text { Life } \\
\text { Sciences \& } \\
\text { Biomedicine }\end{array}$ & $\begin{array}{l}\text { Physical } \\
\text { Sciences }\end{array}$ & $\begin{array}{c}\text { Social } \\
\text { Sciences }\end{array}$ & Technology & Psychology \\
\hline $\begin{array}{l}\text { TP }(M \text { per } \\
\text { year, } S D)\end{array}$ & $\begin{array}{c}11,610(M= \\
236.94, S D= \\
314.97)\end{array}$ & $\begin{array}{c}5,580(M= \\
121.26, S D= \\
148.68)\end{array}$ & $\begin{array}{c}2,133(M= \\
46.37 \\
S D= \\
60.46)\end{array}$ & $\begin{array}{c}3,482(M= \\
79.14, S D= \\
141.72)\end{array}$ & $\begin{array}{c}3,425(M= \\
71.35, S D= \\
110.65)\end{array}$ & $\begin{array}{c}942(M= \\
21.41, S D= \\
30.49)\end{array}$ \\
\hline Journals & 2,504 & 729 & 827 & 1,504 & 1,846 & 271 \\
\hline $\begin{array}{l}\text { TA ( } M \text { per } \\
\text { document) }\end{array}$ & $11,463(.99)$ & $\begin{array}{c}15,860 \\
(2.84)\end{array}$ & $\begin{array}{l}5,445 \\
(2.55)\end{array}$ & $5,377(1.54)$ & $\begin{array}{l}7,556 \\
(2.21)\end{array}$ & $1,942(2.06)$ \\
\hline $\mathrm{CI}$ & 2.13 & 3.08 & 3.21 & 2.52 & 2,72 & 2.6 \\
\hline AGR & $9.76 \%$ & $10.77 \%$ & $12.52 \%$ & $12.59 \%$ & $13.504 \%$ & $9.65 \%$ \\
\hline $\begin{array}{l}\text { TC }(M, \\
\text { Med }(O 1-\end{array}$ & $\begin{array}{l}26,016(M= \\
24 M e d=0\end{array}$ & $\begin{array}{l}100,380 \\
M=1718\end{array}$ & $\begin{array}{c}34,583 \\
M=162\end{array}$ & $\begin{array}{c}26,248(M= \\
754 M e d=1\end{array}$ & $\begin{array}{l}32,485(M= \\
948 M e d=\end{array}$ & $\begin{array}{l}18.638(M= \\
198 M e d=\end{array}$ \\
\hline
\end{tabular}


WHAT COUNTS AS AESTHETICS IN SCIENCE?

Q3)) $\quad(0-2) \quad M e d=7(0-\quad M e d=4(0 \quad(0-5) \quad 1(0-6) \quad 6(0-20)$

19) - 16)

Note. $T P=$ Total publications; $T A=$ Total Authors; $C I=$ Collaboration Index; $A G R=$ Annual growth rate; $T C=$ Total Citations.

Figure 6. The evolution of the six research areas based on the total number of publications and citations.

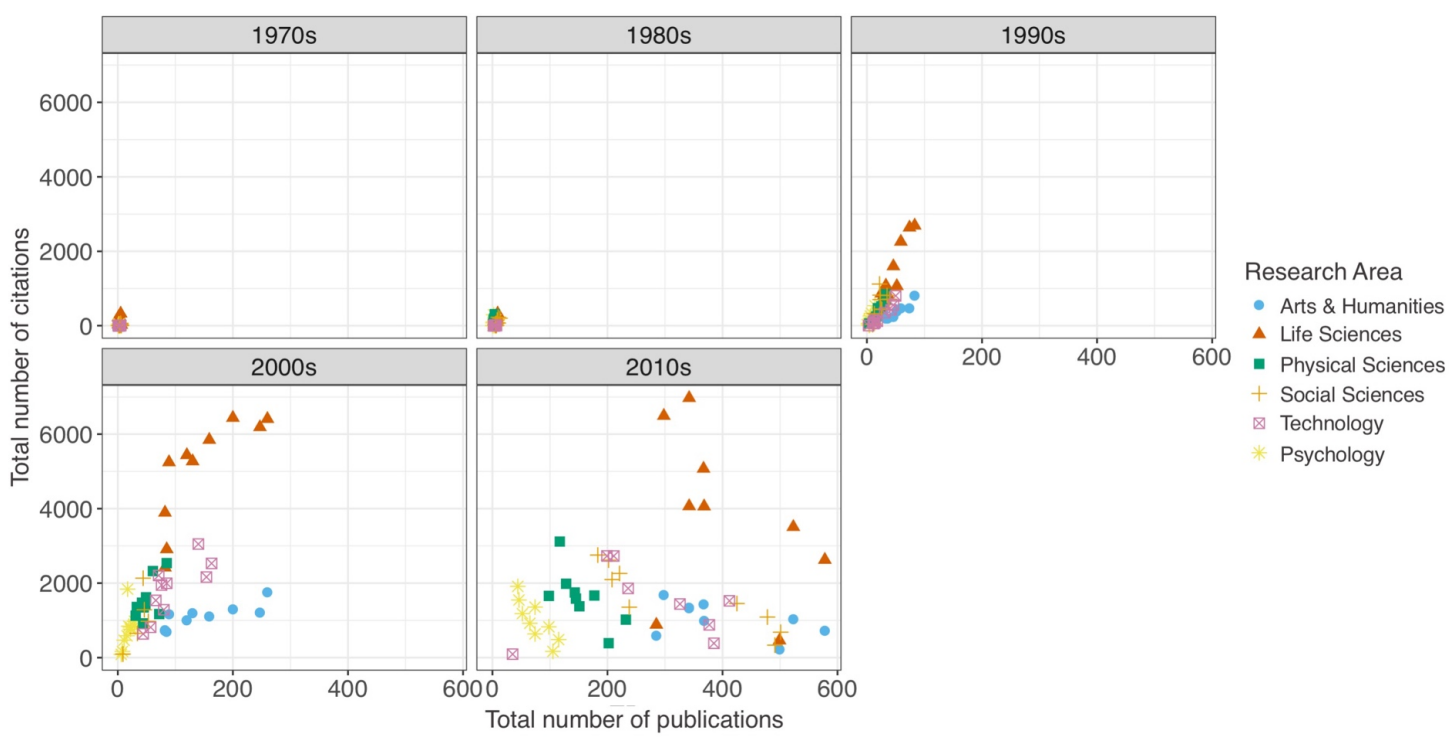

Table 5. Top 10 most frequent keywords in each research areas.

\begin{tabular}{|c|c|c|c|c|c|}
\hline $\begin{array}{l}\text { Arts \& } \\
\text { Humanities }\end{array}$ & $\begin{array}{l}\text { Life Sciences } \\
\& \text { Biomedicine }\end{array}$ & $\begin{array}{l}\text { Physical } \\
\text { Sciences }\end{array}$ & Social Sciences & Technology & Psychology \\
\hline & Dental & Landscape & & & \\
\hline Art (219) & Implants (247) & Aesthetics (49) & Art (106) & Design (96) & Art (62) \\
\hline Ethics (187) & $\begin{array}{l}\text { Quality of life } \\
(92)\end{array}$ & $\begin{array}{l}\text { Landscape } \\
\text { (47) }\end{array}$ & Education (52) & Usability (60) & Beauty (42) \\
\hline Modernism & Dental & Ecosystem & & User Experience & \\
\hline (119) & Esthetics (91) & Services (45) & Design (50) & $(49)$ & Emotion (41) \\
\hline Beauty (114) & $\begin{array}{l}\text { Gingival } \\
\text { Recession (89) } \\
\text { Patient }\end{array}$ & $\begin{array}{l}\text { Biodiversity } \\
(31)\end{array}$ & Ethics (46) & Architecture (46) & $\begin{array}{l}\text { Empirical } \\
\text { Aesthetics (34) }\end{array}$ \\
\hline Politics (97) & $\begin{array}{l}\text { Satisfaction } \\
(81)\end{array}$ & $\begin{array}{l}\text { Sustainability } \\
(30)\end{array}$ & Creativity (41) & $\begin{array}{l}\text { Dental Implants } \\
\text { (44) }\end{array}$ & Preference (34) \\
\hline Kant (84) & Orthognathic & Environmental & Identity (36) & Computational & Music (33) \\
\hline
\end{tabular}


WHAT COUNTS AS AESTHETICS IN SCIENCE?

\begin{tabular}{llllll} 
& Surgery (77) & Aesthetics (24) & & Aesthetics (43) & \\
& Dental Implant & Environment & Performance & Sustainability & Experimental \\
Modernity (78) & $(76)$ & $(21)$ & $(35)$ & $(38)$ & Aesthetics (29) \\
& Orthodontics & Conservation & & $\begin{array}{l}\text { Product Design } \\
\text { Neuroaesthetics }\end{array}$ \\
Poetry (75) & $(76)$ & $(18)$ & Culture (34) & $(37)$ & $(29)$ \\
$\begin{array}{l}\text { Performance } \\
(74)\end{array}$ & Physical & Perception & Architecture & & \\
$\begin{array}{l}\text { Phenomenology } \\
(74)\end{array}$ & Activity (66) & $\begin{array}{l}(18) \\
\text { Decreation }\end{array}$ & $(32)$ & Art (37) & Creativity (27) \\
\hline
\end{tabular}

Note. Total publications per keyword are displayed in brackets. The keywords aesthetics and esthetics are excluded.

\section{Discussion}

Aesthetics research is found in most, if not all, parts of academia. Scholars in the humanities, social science, biology, even physics, have all found cause to engage in research that can be categorized as such. Among this panoply of work, psychologists, and recently also neuroscientists, have a storied tradition of studying questions pertaining to how art is experienced, or why sensory objects become liked and disliked. It remains unclear, though, how these different strands of research relate to each other, or if work that is published in different disciplines under the name of aesthetics deal with a common set of scientific problems. Specifically, it is not clear if different academic research areas count the same topics as part of aesthetics.

We conducted a bibliometric study, analyzing all scientific literature published under the heading of aesthetics between 1970 and 2018, aiming to improve our understanding of what aesthetics is as a scientific enterprise. Using Web of Science, we retrieved a total of 27,169 papers by 45,832 authors that used aesthetics (or esthetics) in their title, abstract, or keywords. The advantage of a bibliometric analysis is that it provides an unbiased characterization of what is and is not aesthetics. Spanning five decades, together the papers tagged as aesthetics reflect how scientists and academics 


\section{WHAT COUNTS AS AESTHETICS IN SCIENCE?}

have conceived of the field in the recent half century: what topics they consider part of aesthetics, which scientific disciplines aesthetics is considered a part of, and how this conception has changed over time. We conducted two sets of analyses, one attempting to give a general picture of the state of aesthetics research in the time period under consideration, and one seeking to describe how different scientific areas differ in their conception of what aesthetics research is.

The primary finding in our first analysis is a conceptual map of aesthetics (Figure 1). This network map shows the most frequent keywords that researchers have used in publications tagged as "aesthetics" and how they relate to each other. Thus, the map summarizes the complex world of aesthetics in a single picture, highlighting its main research trends and themes. By using advanced clustering and natural language processing techniques, the map shows that the keywords cluster into five dissociable areas. The red cluster ("Humanities") is associated with research into topics such as modernism, politics, gender, and identity, and can informally be thought of as linked to disciplines associated with the A\&H (Table 2). The green cluster ("Philosophy") is more philosophical in nature, with a heavier focus on research into art and art-related philosophical topics (Table 2). The yellow cluster ("Empirical Aesthetics") is associated with topics common to what we would think of as psychological aesthetics, including beauty, perception, or design. Finally, while the blue cluster ("Reconstructive Surgery") is exclusively associated with topics related to reconstructive surgery (Table 2), especially as it pertains to the human face, the purple cluster ("Environmental Aesthetics”) groups topics associated with environmental design, including architecture, landscape and sustainability (Table 2).

In many ways this network visualization map conforms to what some will consider a traditional picture of different sub-branches in aesthetics, strongly aligned 


\section{WHAT COUNTS AS AESTHETICS IN SCIENCE?}

with academic sub-divisions and methods. Thus, together the red and green clusters align with disciplines in the humanities and the social sciences, while the other three clusters (yellow, blue, and purple) align with disciplines in the natural and physical sciences. Research hailing from the humanities and social sciences can be characterized as predominantly occupied with questions pertaining to art and art-related meaning, whereas research associated with the latter three clusters seems chiefly associated with appreciation of physical objects, including artworks, the environment, and the human form.

What may surprise about our findings is the prominence of reconstructive surgery in the aesthetics literature surveyed here, both in terms of output and influence. As Table 1 shows, dental implants is the fourth most used keyword associated with the publications we analyze, and journals specializing in dentofacial and reconstructive surgery the most prolific publishers of research tagged as aesthetics. This finding suggests that aesthetics cannot be simply be thought of as either art scholarship, philosophical aesthetics, or empirical aesthetics. We also think it is worthwhile noticing what is not commonly tagged as aesthetics, namely the abundant work on sensory valuation in such fields as animal sexual selection, food hedonics, or neuroeconomics. Even though neuroscientific studies of how body traits or food ingredients elicit preferences overlap with studies of preferences for art, architecture, or human facial properties, at least with respect to their underlying neural mechanisms (Skov, 2019), they are evidently not conceived of as "aesthetic" in nature.

This first analysis also allowed us to identify objective patterns and trajectories that characterize the scientific literature on aesthetics as a whole. First, publications related to aesthetics have increased significantly over time, from less than one hundred publications per year in the 1970 s and 1980 s to more than a thousand publications per 


\section{WHAT COUNTS AS AESTHETICS IN SCIENCE?}

year since 2010 (Figure 2). This finding is congruent with the $3 \%$ general growth of publications observed every year across scientific disciplines (Ware \& Mabe, 2015), with some evidence showing an acceleration in more recent years. However, the total annual percentage growth rate in our dataset was $10.2 \%$, suggesting that research on aesthetics is growing faster than other disciplines. We are not sure what explains this trend, or even if the same explanation applies to the growth spurt witnessed by different disciplines. However, it is possible aesthetics research have benefitted from the rapid advance in recent decades of methods that allow science to probe responses and physiological states associated with aesthetic experiences.

Secondly, the retrieved documents received a total of 217,931 citations, with a mean of $8.02(S D=25.7)$ citations per document. Compared to related disciplines, this average is relatively small. For example, the average citations per article in neuroscience is 187 , in experimental psychology 67 , and in clinical psychology 68 (Patience, Patience, Blais, \& Bertrand, 2017). Across the time span studied here, the average number of times aesthetics publications have been cited has gone up too, with papers published in the last twenty years far more cited than papers published earlier (Figure 3). However, the relationship between year of publications and average number of citations is best described using an inverted-U-shape. The decrease in number of citations observed in the most recent years is likely due the large number of publications emerging in the last decade and the natural gap between publication of an article and the time it receives its first citation (Glänzel, Rousseau, \& Zhang, 2012; Burrell, 2001). For instance, studies published in the humanities took 5 years before half of the articles were cited for the first time, and 15 years when half of the articles were no longer cited (Wang, 2013). 


\section{WHAT COUNTS AS AESTHETICS IN SCIENCE?}

Finally, the country analysis shows that the retrieved literature was produced in a total of 123 countries. However, the contribution of these countries varied largely. When looking at the total number of publications and citations (Appendix B), as well as the international collaborations (Figure 4), it is clear that the U.S. was the most productive country, accounting for $24 \%$ of the total number of publications and $35 \%$ of the total number of citations in the dataset. The UK, China, and Germany were the next most productive countries. Interestingly, this pattern is reversed when taking the population of each country into account (Figure 5). When considering the population for each country, the most productive countries are Slovenia (with 49 publications per million), Denmark (42.2), Australia (41.28), Lithuania (41), and the UK (39.98).

This first analysis is useful in providing a general picture of what aesthetics is as a general research enterprise, how it has evolved over time, and which are the main research trends and themes. However, it is difficult to know how the use of aesthetics has varied across different disciplines and whether these different disciplines differ compared to each other. Furthermore, our analysis of general trends revealed the existence of five main clusters (Figure 1), which largely correspond to different traditions in aesthetics, and to different academic disciplines. Therefore, we sought to explore differences between them in greater detail. To reduce the complexity and subjectivity inherent in the process of categorizing research into different disciplines, we opted to compare five main research areas as defined by WoS. These were A\&H, LS\&B, SS, PS, and T. In addition, we also included a category solely for Psychology (which also included neuroscience).

This comparative analysis (Table 4) indicates that, out of the six surveyed research areas, $\mathrm{A} \& \mathrm{H}$ were responsible for the largest number of papers using the term aesthetics (11,610 publications). However, if taken together, the other four research 


\section{WHAT COUNTS AS AESTHETICS IN SCIENCE?}

areas produced a total of 14,620 aesthetics publications. Thus, perhaps surprisingly, our data suggests more research on aesthetics has been conducted by disciplines that can be thought of as part of the natural and physical sciences than by disciplines in the humanities. The largest research output tagged as aesthetics outside of the humanities is categorized by WoS as part of the LS\&B (5,580 publications). Interestingly, with only half the number of publications produced in the A\&H the category of LS\&B has the largest number of authors $(15,869)$. Aesthetics publications from this research area are also, by far, the most cited aesthetics publications across the six research areas. The least cited aesthetics publications, out of the six research areas, hail from the A\&H. These results suggest that aesthetics research within the arts and humanities is less impactful than research tagged as aesthetics in natural and physical sciences, at least as determined by the number of citations. Moreover, based on the categorization used here, psychology and neuroscience account for 942 publications, $0.03 \%$ of the publications surveyed. It should be noted, though, that the true number of publications produced by these two disciplines is almost certainly much higher, since many of the publications classified as LS\&B or PS here no doubt count as psychology or neuroscience studies. Notably, psychology and neuroscience publications yielded the highest average of citation per document compared to any of the five main research areas $(M=19.8)$. Finally, plotting the evolution of number of publications and citations, we find that, while all six research areas begin expanding in the 1990s, the growth of publication output and citations is especially pronounced for the LS\&B as well as the PS (Figure 6).

Comparison of the different research areas also reveals that aesthetics publications in the $\mathrm{A} \& \mathrm{H}$ are distinguished by their emphasis on philosophical and conceptual topics, including "art", "modernism”, and "beauty" (Table 5). They contribute overwhelmingly to the red and green clusters in Figure 1. In contrast, 


\section{WHAT COUNTS AS AESTHETICS IN SCIENCE?}

aesthetics publications in the LS\&B research area are overwhelmingly concerned with issues related to reconstructive surgery, with a special focus on facial surgery (Table 5), and appear to be the main contributor to the blue cluster in our network analysis.

Similarly, aesthetics publications produced by the PS, centered on landscape aesthetics, forestry, and other forms of environmental aesthetics (Table 5), seem to be the main supplier of research to the purple cluster (Figure 1). Publications associated with research areas SS and T, on the other hand, are much less coherent, and appear to be associated with topics in several of the five keyword clusters. Finally, aesthetics research produced by $\mathrm{P}$ (including neuroscience) can be firmly identified with the yellow cluster in our network model (Figure 1), focused on topics associated with art experience and aesthetic appreciation.

It is important to note that our study has two key limitations. First, we only used one database as the basis for our analysis, namely the Web of Science. There are important reasons for this choice, including the prestige and extensive catalog of WoS, and the fact that it is the only database that allowed us to retrieve such a large number of publications in the desired formats. However, the WoS is not a complete record of all published literature, limited by issues of licensing and sourcing. Not all journals are indexed by WoS. WoS is also dominated by publications and authors who write in English. Thus, our analysis does not incorporate important articles published in other languages. The second limitation concerns the analysis provided in section 2 looking at different research areas. The categorization of research into different disciplines is a complex and subjective task by nature. We had different options here, such as manually assigning journals and publications to different categories. However, this method would be largely subjective and time-consuming. To make the task more objective and replicable, we used the WoS classification to our research areas of interest. It is clear, 


\section{WHAT COUNTS AS AESTHETICS IN SCIENCE?}

though, that journals categorized by, say, LS\&B may very well also contain material that can just as well be categorized as part of Psychology, or other potential research areas.

Together, our findings suggest that aesthetics research is a many-facetted enterprise that spans most of the core research areas in academia. Publications reporting studies tagged as aesthetics can be found in the arts and humanities, physical and social sciences, as well as the life science and technology. Interestingly, our analysis reveals that these research areas vary in the kind of topics they associate aesthetics with. As a whole, aesthetics research coalesces into five different domains, with limited contact, that can be distinguished in terms of the topics they pursue. Our keyword analysis suggests that the twin topics of art experience and aesthetic appreciation remain central to research dubbed aesthetics. Yet, it also shows that aesthetics is associated with many topics that go beyond these two. In the red cluster aesthetics research encompasses topics such as nationalism, globalization, or identity, while in blue and purple clusters topics include conservation, sustainability, and quality of life. Furthermore, it is important to note that several keywords, in some of the research domains, suggest that an important parts of aesthetics research is concerned with aesthetics as intervention, not just as a response to art or other sensory objects, especially research that bear on environmental design and human plastic surgery. Meanwhile, our analysis also demonstrate that scientific research that could conceivably be categorized as aesthetics, such as hedonic feeding or sexual selection research, are not. In going forward, we believe it will important to aesthetics to make a note of this variety of interests and diversity in academic traditions. We also believe the ubiquity of aesthetics, and the increasing impact of its publication, suggest that aesthetics research is poised to improve its status as a scientific enterprise. 


\section{WHAT COUNTS AS AESTHETICS IN SCIENCE?}

\section{References}

Allesch, C.G. (1987): Geschichte der psychologischen Ästhetik. Göttingen: Verlag für Psychologie.

Anglada-Tort, M., \& Sanfilippo, K.R.M. (2019). Visualizing music psychology: A bibliometric analysis of Psychology of Music, Music Perception, and Musicae Scientiae from 1973 to 2017. Music \& Science, 2, 2059204318811786.

Aria, M., \& Cuccurullo, C. (2017). bibliometrix: An R-tool for comprehensive science mapping analysis. Journal of Infor- metrics, 11, 959-975.

Baumgarten, A.G. (1735/1954). Reflections on poetry: Alexander Gottlieb Baumgarten's Meditationes philosophicae de nonnullis ad poema pertinentibus. Berkeley and Los Angeles: University of California Press.

Becker, S., Bräscher, A-K., Bannister, S., Bensafi, M., Calma-Birling, D., Chan, R.C.K., Eerola, T., Ellingsen, D-M., (...), \& Wang, Y. (2019). The role of hedonics in the Human Affectome. Neuroscience and Biobehavioral Reviews, 102, 221-241.

Berridge, K.C., \& Kringelbach, M.L. (2015). Pleasure systems in the brain. Neuron, 86, 646664.

Brattico, E., \& Pearce, M. (2013). The neuroasthetics of music. Psychology of Aesthetics, Creativity, and the Arts, 7, 48-61.

Brielmann, A.A., \& Pelli, D.G. (2017). Beauty requires thought. Current Biology, 27, 15061513.

Burrell, Q. L. (2001). Stochastic modelling of the first citation distribution. Scientometrics, 52, 3-12. doi:10.1023/A:1012751509975

Chatterjee, A. (2011). Neuroaesthetics: A coming of age story. Journal of Cognitive Neuroscience, 3, 53-62. 


\section{WHAT COUNTS AS AESTHETICS IN SCIENCE?}

Chatterjee, A., \& Vartanian, O. (2014). Neuroaesthetics. Trends in Cognitive Sciences, 18, 370375.

Chatterjee, A., \& Vartanian, O. (2016). Neuroscience of aesthetics. Annals of the New York Academy of Sciences, 1369, 172-194.

Chen, S., Arsenault, C., Gingras, Y., \& Larivière, V. (2015). Exploring the interdisciplinary evolution of a discipline: the case of Biochemistry and Molecular Biology. Scientometrics, 102(2), 1307-1323.

Croft, J. (2011): The challenges of interdisciplinary epistemology in neuroaesthetics. Mind, Brain, and Education, 5(1), 5-11.

De Bellis, N. (2009). Bibliometrics and citation analysis: from the science citation index to cybermetrics. Lanham, MD: Scarecrow Press.

Dickie, G. (1962). Is psychology relevant to aesthetics? Philosophical Review, 71, 285-302.

Di Dio, C., \& Gallese, V. (2009). Neuroaesthetics: A review. Current Opinion in Neurobiology, 19, 682-687.

Garfield, E. (1972). Citation analysis as a tool in journal evaluation. Science, 178, 471-479.

Glänzel, W., Rousseau, R., \& Zhang, L. (2012). A visual representation of relative first citation times. Journal of the American Society for Information Science and Technology, 63, 1420-1425. doi:10.1002/ asi.22643

Fechner, G. T. (1876). Vorschule der Ästhetik [Preliminaries of Aesthetics]. Leipzig, Germany: Breitkopf und Härtel.

Hodges, D.A. (2018). The neuroaesthetics of music. In S. Hallam, I. Cross \& M. Thaut (Eds.), The Oxford Handbook of Music Psychology (pp. 1-20). DOI:

10.1093/oxfordhb/9780198722946.013.20

Huston, J.P., Nadal, M., Mora, F., Agnati, L.F. \& Cela-Conde, C.J. (2015). Art, Aesthetics, and the Brain. Oxford: Oxford University Press. 


\section{WHAT COUNTS AS AESTHETICS IN SCIENCE?}

Hyman, J. (2010). Art and neuroscience. In R. Frigg \& M.C. Hunter (eds.), Beyond Mimesis and Convention (pp. 245-261). Amsterdam: Springer. DOI: 10.1007/978-90-481-3851$7 \_11$

Jacobsen, T. (2006). Bridging the Arts and Sciences: A Framework for the Psychology of Aesthetics. Leonardo, 39(2), 155-162.

Meskin, A., Robson, J., Ichino, A., Goffin, K., \& Monseré, A. (2018). Philosophical aesthetics and cognitive science. WIREs Cognitive Science, 9, e1445. DOI: 10.1002/wcs. 1445

Mryglod, O., Holovatch, Y., Kenna, R., \& Berche, B. (2016). Quantifying the evolution of a scientific topic: reaction of the academic community to the Chornobyl disaster. Scientometrics, 106(3), 1151-1166.

Nadal, M., Gomila, A. \& Gálvez-Pol, A. (2014). A history for neuroasthetics. In J.O. Lauring (Ed.), An Introduction to Neuroaesthetics (pp. 3-50). Copenhagen: Museum Tusculanum Press.

Nadal, M., \& Pearce, M. (2011). The Copenhagen Neuroaesthetics conference: Prospects and pitfalls for an emerging field. Brain and Cognition, 76, 172-183.

Naukkarinen, O., \& Bragge, J. (2016). Aesthetics in the age of digital humanities. Journal of Aesthetics \& Culture, 8(1), 30072. DOI: 10.3402/jac.v8.30072

Noë, A. (2015). Strange Tools: Art and Human Nature. New York, NY: Hill and Wang.

Patience, G. S., Patience, C. A., Blais, B., \& Bertrand, F. (2017). Citation analysis of scientific categories. Heliyon, 3, e00300.

Pearce, M.T., Zaidel, D.W., Vartanian, O., Skov, M., Leder, H., Chatterjee, A., \& Nadal, M. (2016). Neuroaesthetics: The cognitive neuroscience of aesthetic experience. Perspectives on Psychological Science, 11, 265-279. 


\section{WHAT COUNTS AS AESTHETICS IN SCIENCE?}

Rangel, A., Camerer, C., \& Montague, P.R. (2008). A framework for studying the neurobiology of value-based decision making. Nature Reviews Neuroscience, 9, 545556.

Reiss, H. (1994). The "naturalization” of the term “Ästhetik" in eighteenth-century German: Alexander Gottlieb Baumgarten and his impact. The Modern Language Review, 89, $645-658$.

Skov, M. (2019). The neurobiology of sensory valuation. In M. Nadal \& O. Vartanian (Eds.), The Oxford Handbook of Empirical Aesthetics (pp. 1-40). Oxford: Oxford University Press. DOI: 10.1093/oxfordhb/9780198824350.013.7

Skov, M., \& Vartanian, O. (2009): Neuroaesthetics. Amityville, NY: Baywood.

Sweileh, W. M. (2017). Global research trends of World Health Organization's top eight emerging pathogens. Globalization and Health, 13, 9. doi:10.1186/s12992-017-0233-9

Sweileh, W. M., Al-Jabi, S. W., AbuTaha, A. S., Zyoud, S. H., Anayah, F. M. A., \& Sawalha, A. F. (2017). Bibliometric analysis of worldwide scientific literature in mobile - health: 2006-2016. BMC Medical Informatics and Decision Making, 17, 1-12. doi:10.1186/s12911-017-0476-7

South, A. (2011). rworldmap: A New R package for Mapping Global Data. R Journal, 3. 35-43. Thomson Reuters (2010). Web of Science. Retrieved from https://clarivate.com/webofsciencegroup/solutions/web-of-science/ Thomson Reuters (2017, February). Web of Knowledge - Real Facts. Retrieved from https://web.archive.org/web/20170224013916/http://wokinfo.com/citationconnection/re $\underline{\text { alfacts }}$

van Eck, N. J., \& Waltman, L. (2010). Software survey: VOS- viewer, a computer program for bibliometric mapping. Scien- tometrics, 84, 523-538. doi:10.1007/s11192-009-0146-3 


\section{WHAT COUNTS AS AESTHETICS IN SCIENCE?}

Van Steenbergen, H., Eikemo, M., \& Leknes, S. (2019). The role of the opioid system in decision making and cognitive control: A review. Cognitive, Affective \& Behavioral Neuroscience, 19, 435-458.

Waltman, L., Van Eck, N. J., \& Noyons, E. C. (2010). A unified approach to mapping and clustering of bibliometric networks. Journal of Informetrics, 4, 629-635.

Wang, J. (2013). Citation time window choice for research impact evaluation. Scientometrics, 94(3), 851-872.

Ware, M., \& Mabe, M. (2015). The STM report: An overview of scientific and scholarly journal publishing. Retrieved from http://digitalcommons.unl.edu/scholcom/9 
WHAT COUNTS AS AESTHETICS IN SCIENCE?

\section{Appendix A}

Citation analysis per year.

\begin{tabular}{|c|c|c|c|c|}
\hline Year & ТP (\%) & $\mathrm{TC}$ & Mean (SD) & Median (Q1-Q3) \\
\hline 1970 & $27(0.1)$ & 384 & $14.22(57.62)$ & $2(0-5)$ \\
\hline 1971 & $20(0.07)$ & 45 & $2.25(3.24)$ & $0.5(0-4.25)$ \\
\hline 1972 & $13(0.05)$ & 57 & $4.39(9.76)$ & $1(0-2)$ \\
\hline 1973 & $14(0.05)$ & 286 & $20.43(58.48)$ & $0(0-13.5)$ \\
\hline 1974 & $12(0.04)$ & 40 & $3.33(5.99)$ & $1(0-3.5)$ \\
\hline 1975 & $75(0.28)$ & 220 & $2.93(6.3)$ & $0(0-2.5)$ \\
\hline 1976 & $81(0.3)$ & 201 & $2.48(5.21)$ & $0(0-2)$ \\
\hline 1977 & $61(0.22)$ & 175 & $2.87(5.82)$ & $0(0-3)$ \\
\hline 1978 & $58(0.21)$ & 372 & $6.41(21.88)$ & $2(0-4)$ \\
\hline 1979 & $75(0.28)$ & 183 & $2.44(6.31)$ & $0(0-3)$ \\
\hline 1980 & $87(0.32)$ & 625 & $7.18(19.16)$ & $1(0-4)$ \\
\hline 1981 & $98(0.36)$ & 207 & $2.11(8.18)$ & $0(0-1.75)$ \\
\hline 1982 & $84(0.31)$ & 415 & $4.94(14.77)$ & $0.5(0-2)$ \\
\hline 1983 & $117(0.43)$ & 351 & $3(13.27)$ & $0(0-2)$ \\
\hline 1984 & $91(0.33)$ & 269 & $2.96(9.63)$ & $0(0-1)$ \\
\hline 1985 & $96(0.35)$ & 265 & $2.76(7.08)$ & $0(0-2)$ \\
\hline 1986 & $108(0.4)$ & 251 & $2.32(4.88)$ & $0(0-2)$ \\
\hline 1987 & $91(0.33)$ & 664 & $7.3(33.25)$ & $0(0-2.5)$ \\
\hline 1988 & $99(0.36)$ & 556 & $5.62(19.1)$ & $1(0-2)$ \\
\hline 1989 & $107(0.39)$ & 568 & $5.31(18.2)$ & $0(0-2)$ \\
\hline 1990 & $108(0.4)$ & 351 & $3.25(7.35)$ & $1(0-3)$ \\
\hline 1991 & $166(0.61)$ & 1248 & $7.52(18.06)$ & $1(0-6.75)$ \\
\hline
\end{tabular}


WHAT COUNTS AS AESTHETICS IN SCIENCE?

\begin{tabular}{|c|c|c|c|c|}
\hline 1992 & $167(0.61)$ & 1726 & $10.34(26.89)$ & $1(0-5.5)$ \\
\hline 1993 & $207(0.76)$ & 1775 & $8.58(22.13)$ & $2(0-7)$ \\
\hline 1994 & $186(0.68)$ & 2611 & $14.04(29.97)$ & $1(0-10)$ \\
\hline 1995 & $216(0.8)$ & 3156 & $14.61(35.42)$ & $2(0-10)$ \\
\hline 1996 & $242(0.89)$ & 2702 & $11.17(24.24)$ & $2(0-10)$ \\
\hline 1997 & $276(1.02)$ & 4086 & $14.8(38.5)$ & $2(0-10)$ \\
\hline 1998 & $288(1.06)$ & 5503 & $19.11(51.54)$ & $3(0-16)$ \\
\hline 1999 & 375 (1.38) & 4772 & $12.73(30.05)$ & $2(0-9)$ \\
\hline 2000 & $376(1.38)$ & 6909 & $18.38(42.36)$ & $3(0-14)$ \\
\hline 2001 & 379 (1.39) & 5990 & $15.81(50.18)$ & $2(0-11)$ \\
\hline 2002 & 399 (1.47) & 6227 & $15.61(33.44)$ & $3(0-16.5)$ \\
\hline 2003 & $416(1.53)$ & 10709 & $25.74(69.39)$ & $4(0-22)$ \\
\hline 2004 & $452(1.66)$ & 11847 & $26.21(63.54)$ & $6(1-21)$ \\
\hline 2005 & $508(1.87)$ & 9650 & $19(45.06)$ & $4.5(1-18)$ \\
\hline 2006 & 567 (2.09) & 10481 & $18.49(40.79)$ & $5(0-17.5)$ \\
\hline 2007 & 730 (2.69) & 12797 & $17.53(38.66)$ & $4(0-19)$ \\
\hline 2008 & $901(3.32)$ & 12125 & $13.46(27.3)$ & $3(0-14)$ \\
\hline 2009 & 987 (3.63) & 13500 & $13.68(26.82)$ & $4(0-15)$ \\
\hline 2010 & $1140(4.2)$ & 14344 & $12.58(24.63)$ & $3(0-13)$ \\
\hline 2011 & $1241(4.57)$ & 14332 & $11.55(28.78)$ & $3(0-11)$ \\
\hline 2012 & $1326(4.88)$ & 12597 & $9.5(23.54)$ & $3(0-10)$ \\
\hline 2013 & $1420(5.23)$ & 11094 & $7.81(17.74)$ & $2(0-9)$ \\
\hline 2014 & $1536(5.65)$ & 8953 & $5.83(12.8)$ & $1(0-6)$ \\
\hline 2015 & $2544(9.36)$ & 8940 & $3.51(9.68)$ & $1(0-3)$ \\
\hline 2016 & $2719(10.01)$ & 7176 & $2.64(6.49)$ & $0(0-2)$ \\
\hline
\end{tabular}


WHAT COUNTS AS AESTHETICS IN SCIENCE?

$\begin{array}{ccccc}2017 & 2988(11) & 4554 & 1.52(4.14) & 0(0-1) \\ 2018 & 2893(10.65) & 1642 & 0.57(1.64) & 0(0-0)\end{array}$

Note. TP: Total publications; TC: Total citations. 
WHAT COUNTS AS AESTHETICS IN SCIENCE?

\section{Appendix B}

Top 20 most productive countries (country of corresponding author).

\begin{tabular}{|c|c|c|c|c|c|}
\hline Country & $\mathrm{TP}(\%)$ & SCP & SMP & $\mathrm{TC}$ & M TC \\
\hline US & $6622(24.37)$ & 121 & 6501 & 75452 & 11.39 \\
\hline UK & $2359(8.68)$ & 59 & 2300 & 24081 & 10.21 \\
\hline China & $1519(5.59)$ & 121 & 1398 & 5081 & 3.35 \\
\hline Germany & $1211(4.46)$ & 22 & 1189 & 11189 & 9.24 \\
\hline Brazil & 1003 (3.69) & 9 & 994 & 4531 & 4.52 \\
\hline Canada & $967(3.56)$ & 36 & 931 & 10914 & 11.29 \\
\hline Italy & 759 (2.79) & 16 & 743 & 7593 & 10.00 \\
\hline France & $746(2.75)$ & 19 & 727 & 3179 & 4.26 \\
\hline Australia & $743(2.73)$ & 15 & 728 & 9997 & 13.45 \\
\hline Spain & $738(2.72)$ & 11 & 727 & 3194 & 4.33 \\
\hline India & $520(1.91)$ & 3 & 517 & 1254 & 2.41 \\
\hline Turkey & $412(1.52)$ & 9 & 403 & 2583 & 6.27 \\
\hline Netherlands & $403(1.48)$ & 12 & 391 & 6247 & 15.50 \\
\hline Russia & $347(1.28)$ & 6 & 341 & 130 & 0.37 \\
\hline Taiwan & $336(1.24)$ & 11 & 325 & 2365 & 7.04 \\
\hline Korea & $328(1.21)$ & 0 & 328 & 2319 & 7.07 \\
\hline Japan & $317(1.17)$ & 8 & 309 & 2285 & 7.21 \\
\hline Sweden & $298(1.1)$ & 12 & 286 & 3876 & 13.01 \\
\hline Switzerland & $272(1)$ & 3 & 269 & 5925 & 21.78 \\
\hline Belgium & $244(0.9)$ & 9 & 235 & 4339 & 17.78 \\
\hline
\end{tabular}

Note. TP: Total Publications; SCP: Single Country Publication; MCP: Multiple

Country Publication; TC: Total Citations; M TC: Mean Total Citation per publication. 